\title{
Vitamin status in treated patients with cystic fibrosis
}

\author{
P J CONGDEN, G BRUCE, M M ROTHBURN, P C N CLARKE, J M LITTLEWOOD, \\ J KELLEHER, AND M S LOSOWSKY
}

Department of Paediatrics and Department of Medicine, St James's University Hospital, Leeds, and Department of Paediatrics, Harrogate District Hospital, Yorks

SUMmARY The water-soluble (B1, B2, B6, C, folic acid) and fat-soluble vitamin (A, carotene, E, and D) status of 36 patients with cystic fibrosis was assessed and compared with a control group of 21 age-matched normal children. Twenty-seven of the patients were receiving vitamin supplements (except folic acid and vitamin E) at the time of investigation. Vitamin B1, B2, and B6 status was adequate in all patients, and there was little evidence of folic acid deficiency. Vitamin $\mathrm{C}$ stores might not have been adequate in some of these patients, despite daily supplements with $50 \mathrm{mg}$ of the vitamin. Steatorrhoea, often severe, was present in most of them. Serum carotene and vitamin E concentrations were low in over $90 \%$ of patients and were related to the severity of steatorrhoea. Vitamin A was low in over $40 \%$ of the patients despite daily vitamin supplements of $4000 \mathrm{IU}$ and correlated with the serum retinol-binding protein level. Serum $25-\mathrm{OH}$ cholecalciferol was low in some patients whether or not they were receiving a daily supplement of 400 IU vitamin D. In a short-term supplementation trial with water-miscible preparations of vitamins $A$ and $E$ in 14 patients, the serum levels of both vitamins responded well to 2 weeks of treatment with $50 \mathrm{mg}$ vitamin E and $4000 \mathrm{IU}$ vitamin A. Except for serum vitamin A, which was lowest in patients with the poorest clinical grading, the other vitamins were not influenced by the clinical grade of the patients.

Cystic fibrosis occurs in about $1 / 2000$ of live births in white Europeans, the majority of new cases now being diagnosed soon after birth. Life expectancy has been greatly improved by early vigorous treatment, ${ }^{1-4}$ and has resulted in an increasing population of patients who will require life-long medical care. Pancreatic insufficiency is present in over $80 \%$ of patients with cystic fibrosis. ${ }^{1}$ The resulting fat malabsorption is often severe and may not respond well to pancreatic replacement. ${ }^{56}$ Although gastrointestinal absorption of fat-soluble vitamins is impaired in patients with steatorrhoea and correlates with its severity, ${ }^{7}$ clinical deficiency, manifested by bone disease (rickets) or severe bleeding, is rare in cystic fibrosis, although it does occur. $^{8}{ }^{9}$

Symptoms are mainly a consequence of pulmonary infection and pancreatic insufficiency and there is great variation in the presentation and severity of symptoms. ${ }^{10}$ Malnutrition can be a major complication of cystic fibrosis, ${ }^{11}{ }^{12}$ resulting in the main from pancreatic insufficiency, ${ }^{13}$ and in younger children is manifested in poor weight gain and growth. It has been stressed that improvement of nutritional status is important for growth into adolescence ${ }^{14}$ and the subsequent quality of life. Many different dietary manipulations have been recommended and it is generally accepted that vitamin deficiencies should be avoided. This is especially important with regard to the fat-soluble vitamins. ${ }^{15}$ Almost all patients with cystic fibrosis, from the time of diagnosis, are given a daily multivitamin preparation containing water-soluble vitamins as well as the fat-soluble vitamins $A$ and $D$. Vitamins $E$ and $K$ are not consistently supplemented. The quantity of vitamins given is generally twice the recommended intake for age, ${ }^{16} 17$ but this appears to be quite arbitrary, and there is little evidence that these supplements are adequate except for vitamin $\mathrm{A}$, which has been widely studied. Despite prolonged supplementation, deficiencies of vitamin $\mathrm{A}$ are common. ${ }^{18}{ }^{19} \mathrm{~A}$ need therefore exists to assess the vitamin status of patients with cystic fibrosis during treatment, and to determine if present practice of vitamin supplementation is adequate.

The purpose of the present study was to measure a wide spectrum of blood vitamin levels in patients with cystic fibrosis. The adequacy of conventional vitamin supplements was assessed, and the level of fat-soluble vitamins was related to the severity of fat 
malabsorption. The effect of short-term supplementation with water-miscible forms of vitamins A and $\mathrm{E}$ was also assessed.

\section{Patients studied}

Thirty-six patients with cystic fibrosis (19 girls and 17 boys) were studied. Age range was 10 months to 16 years (girls 10 months- 15 years 3 months; boys 2 years 1 month-16 years). All patients were diagnosed by positive sweat tests, and recurrent pulmonary symptoms. Steatorrhoea was present in 23 of 26 patients tested. None of the patients was in hospital at the time of investigation and all were attending a regular outpatient clinic. At the time of investigation, each patient was graded clinically by a modification of the grading system of Shwachman and Kulczycki ${ }^{20}$ as described by Doershuk et al. ${ }^{21}$ based on (1) case history, (2) pulmonary findings, (3) growth and nutrition, and (4) radiology of chest. Each category was graded $0-25$ in fives, the best grading attainable in each category being 25 . Thus the highest grading possible was 100 .

All patients were receiving treatment at the time of investigation; 32 patients were receiving pancreatic supplements in varying quantities dependent on age and symptoms; 28 were receiving continuous antibiotics, usually cloxacillin or flucloxacillin, or both, and 27 were receiving vitamin supplements to provide twice the recommended intake for age (24 Abidec and 3 Ketovite). Twenty-six patients were on a low dietary fat intake and 15 of them were receiving medium chain triglycerides as a vegetable oil for cooking in the older children or as a medium chain triglyceride milk (Portagen) in younger children.

Results in patients with cystic fibrosis were compared with a group of 21 control children in good nutritional state, as judged by height and weight for age and without evidence of gastrointestinal or pancreatic disease. These children were the offspring of the authors, or were children attending the outpatient clinic who had had a venepuncture for some other purpose. There were 10 boys and 11 girls in this group, age range 1 to 16 years.

\section{Materials and methods}

As these children were outpatients, some of whom had travelled long distances to attend the clinic, it was felt unreasonable to expect them to fast. They were advised to take a light breakfast excluding any vitamin-rich foods or drink on the day of investigation. Vitamin supplements were not taken until after they had attended the clinic; thus no patient received a vitamin supplement within 18 hours of the time of venepuncture. Blood was collected using heparin and sequestrene as anticoagulants. Specimens from control children were collected at similar times and using the same dietary restrictions. Owing to the range and complexity of the analytical assays, only 2 subjects could be coped with each week, thus the specimens from patients and controls were collected over a period of almost 12 months from October 1977 to August 1978.

\section{Vitamin assays.}

\section{Ascorbic acid (vitamin C)}

Vitamin $C$ was measured in leucocytes plus platelets by the method of Denson and Bowers. ${ }^{22}$

\section{Folic acid}

Plasma and erythrocyte folic acid was assayed by radioimmunoassay using a commercially available kit (Becton Dickinson UK Ltd).

\section{Vitamin B1, B2, and B6}

These vitamins were assessed by assaying the activity of erythrocyte enzymes requiring them as co-factors before and after addition of the appropriate co-factor in vitro. The value is expressed as a ratio of the activity after and before addition of the co-factor. Thus a high ratio is an indication of possible vitamin deficiency or depletion. Transketolase (EC 2.2.1.1) was assayed in the presence and absence of thiamine pyrophosphate, to determine vitamin B1 status, by the method of Schouten et al. ${ }^{23}$ Glutathione reductase (EC 1.6.4.2) was assayed in the presence and absence of added flavin adenine dinucleotide, to determine vitamin B2 status, by the method of Nichoalds. ${ }^{24}$ Glutamic-oxaloacetic transaminase (EC 2.6.11) was assayed in the presence and absence of pyridoxal phosphate to determine vitamin B6 status, by the method of Stanoluvic et al. $^{25}$

\section{Vitamin A}

Vitamin A was assayed spectrofluorimetrically after hexane extraction. ${ }^{26}$

\section{Carotene}

Plasma carotene was assayed spectrophotometrically at $520 \mathrm{~nm}$ after petroleum ether extraction. ${ }^{27}$

\section{5-OH-cholecalciferol}

Plasma 25-OH-cholecalciferol was assayed by competitive protein binding assay. ${ }^{28}$

\section{Vitamin $E$}

Plasma tocopherol was measured spectrophotometrically after reaction with bathophenanthroline 
by a modification of the procedure of Fabianek et al. $^{29}$

Retinol binding protein and low-density $(\beta)$ lipoprotein These were assayed by radial immunodiffusion on commercially available agar plates (Hoechst Pharmaceuticals Ltd).

\section{Faecal fat}

Polyethylene glycol 4000 was used as a nonabsorbable marker and determined by the method of Hyden..$^{30}$ Polyethylene glycol 4000 was administered in a dose of $250 \mathrm{mg}$ 3-times daily one dose with each main meal for 7 days and faeces collected on day 6-7. Faecal fat was determined on 2-day faecal collections $^{31}$ by the method of van de Kamer et al..$^{32}$ and corrected for polyethylene glycol recovery.

Assays for vitamins B2, B6, and C were performed on the same day as the specimen was received; all other assays were performed within one week of collection.

\section{Water-miscible vitamin A/E supplementation}

This was given to 14 patients, aged 1 year 8 months to 17 years, who continued with their usual treatment including vitamin supplements. A blood sample was obtained at the beginning of the treatment period. The patients then received $50 \mathrm{mg}$ of water-miscible $\alpha$-tocopherol as an emulsion in cremophor (Roche Products Ltd, Welwyn Garden City, UK) and 4000 IU of water-miscible vitamin A acetate as gelatincoated beadlets (Roche Products Ltd) a day for 2 weeks. On the 15 th day ( 24 hours after the last vitamin dose) a second blood sample was obtained after an overnight fast.

\section{Results}

Clinical grade. This was available in $\mathbf{3 5}$ out of the 36 patients with cystic fibrosis. The gradings were as follows: $<75$ in nine, $75-80$ in nine, $85-90$ in ten, and at least 95 in seven. Pulmonary findings and growth and nutrition were the most common abnormal grading categories. For growth and nutrition, 17 of 35 patients had a grading of 15 or less, while for pulmonary symptoms 11 of 35 had a grading of 15 or less.

Vitamins B1, B2, and B6. The Table shows the enzyme activation coefficients found for the control and patient groups; there is close similarity between them. For vitamins B2 and B6, all values were within 2 SD of the control mean. Minor abnormalities of vitamin B1 were found in 3 patients who had enzyme activation ratios of $1 \cdot 15,1 \cdot 15$, and $1 \cdot 16$ which were just outside the upper limit of $1 \cdot 14$ found
Table Enzyme activation tests (mean $\pm 1 S D)$

\begin{tabular}{lccc}
\hline & Vitamin B1 & Vitamin B2 & Vitamin B6 \\
\hline Controls $(\mathrm{n}=20)$ & $1.02 \pm 0.06$ & $1 \cdot 15 \pm 0.13$ & $1.63 \pm 0.19$ \\
Cystic fibrosis $(\mathrm{n}=29)$ & $1.04 \pm 0.07$ & $1.04 \pm 0 \cdot 15$ & $1.49 \pm 0.13$ \\
Significance & $\mathrm{NS}$ & $\mathrm{NS}$ & $\mathrm{NS}$ \\
\hline
\end{tabular}

in the control group. Thus B1, B2, and B6 status in this group of patients was apparently adequate. Vitamin B1, B2, and B6 status was also normal in 7 patients who were not receiving vitamin supplements.

Folic acid. Except for the 3 receiving Ketovite, patients were not receiving folic acid supplements and little evidence of deficiency was found. Only one patient had a low serum folate level $(2 \cdot 5 \mathrm{ng} / \mathrm{ml}$, lower limit of normal 3.0) and this subject had a normal erythrocyte folate $(178 \mathrm{ng} / \mathrm{ml}$, lower limit of normal 122). Two further patients had low erythrocyte folate levels, 70 and $90 \mathrm{ng} / \mathrm{ml}$ in the presence of normal serum folate, $3 \cdot 2$ and $3 \cdot 4 \mathrm{ng} / \mathrm{ml}$ respectively. The haemoglobin concentration and blood films were normal in these 3 subjects.

Vitamin C. Leucocyte plus platelet vitamin C levels in the control and cystic fibrosis groups are shown in Fig. 1. Only 3 patients out of 30 were below the control range. Two of them had low levels despite receiving vitamin $C$ supplements of $50 \mathrm{mg} /$ day. Several other patients were at the lower limit of the normal range. Five patients out of the 30 in whom vitamin $\mathrm{C}$ values were available were not receiving

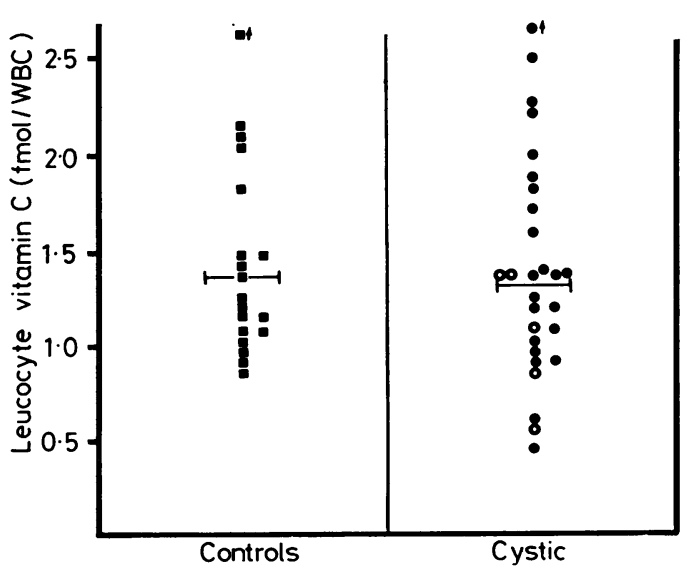

Fig. 1 Leucocyte vitamin C levels in control children and patients with cystic fibrosis. Vitamin $C$ supplemented patients are shown as $(\bullet)$ and those not receiving supplements as (0). Horizontal bar shows the mean for each group. 


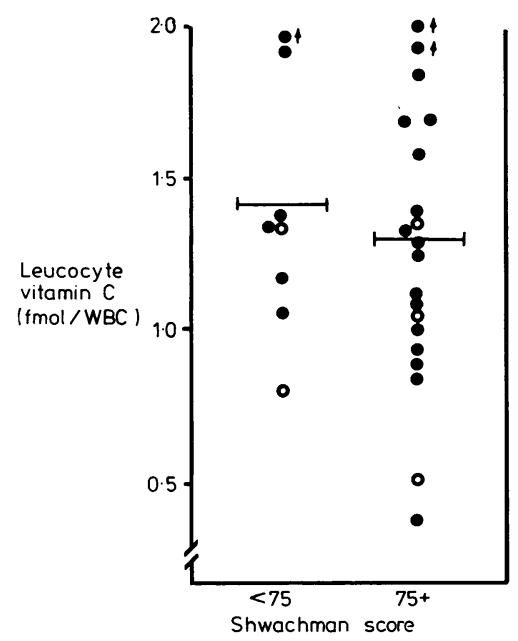

Fig. 2 Leucocyte vitamin C levels in two groups of patients with cystic fibrosis. The groups were selected on the basis of clinical grading (see text). Vitamin C supplemented patients are shown as (๑) and those not receiving supplements as (0). Horizontal bars show the mean for each group.

additional vitamin $\mathrm{C}$ and their levels were similar to those of the supplemented group.

The clinical state as assessed by the Shwachman score had little relation to leucocyte vitamin C levels (Fig. 2). Patients were arbitrarily divided into two groups, above and below a score of 75 , and the range of values in each group was similar (Fig. 2).

The clinical state of the patients had little, if any, relationship to the blood levels of any of the other water-soluble vitamins.

Faecal fat. Only 4 of 26 patients tested had a normal faecal fat $(<17.6 \mathrm{mmol} / 24 \mathrm{~h} ; 5 \mathrm{~g} / 24 \mathrm{~h})$ despite regular pancreatic enzyme replacement treatment in all patients except one. Streatorrhoea was often severe; 10 patients had values greater than 100 $\mathrm{mmol} / 24 \mathrm{~h}(28.4 \mathrm{~g} / 24 \mathrm{~h})$, and 17 had values above $50 \mathrm{mmol} / 24 \mathrm{~h}(14 \cdot 2 \mathrm{~g} / 24 \mathrm{~h})$.

Carotene. Serum carotene was normal in only one patient of 28 tested. Normal range in 20 control children was $2 \cdot 10 \pm 0 \cdot 211 \mathrm{SE} \mu \mathrm{mol} / \mathrm{l}$. Ten patients had values below $0.4 \mu \mathrm{mol} / 1$, while 23 patients $(82 \%$ of total) had values below $0 \cdot 8 \mu \mathrm{mol} / 1$. The correlation between serum carotene and faecal fat, although significant $(r=0.41 \mathrm{P}<0.05)$, was not close.

Vitamin A. Despite supplementation with up to 4000 IU a day, a high proportion of patients had low serum vitamin A levels (Fig. 3). The normal range
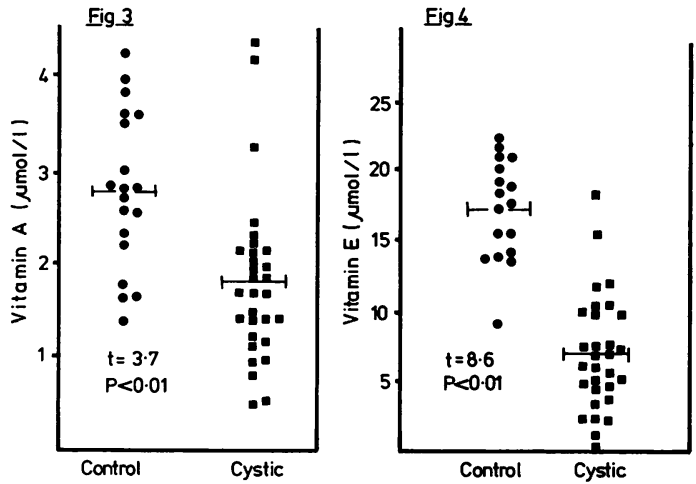

Fig. 3 Serum vitamin A levels in control children and children with cystic fibrosis. Horizontal bars show the mean for each group.

Fig. 4 Serum vitamin E levels in control children nad children with cystic fibrosis. Horizontal bars show the mean for each group.

found was $2 \cdot 83 \pm 0 \cdot 20 \mu \mathrm{mol} / \mathrm{l}$, the levels in patients with cystic fibrosis $(1.98 \pm 0 \cdot 161 \mathrm{SE} \mu \mathrm{mol} / \mathrm{l})$ being significantly lower $(t=3.7 \quad \mathrm{P}<0.01)$. Thirteen $(43 \%)$ of 30 patients had values more than 2 SD below the mean for the controls. Retinol-binding protein (RBP) was present in significantly lower concentrations $(t=3.99 \mathrm{P}<0.01)$ in the patients $(34 \pm 1.8 \mu \mathrm{g} / \mathrm{ml})$ than in the controls $(60 \cdot 7 \pm 4.3$ $\mu \mathrm{g} / \mathrm{ml}), 18(67 \%)$ of 27 being more than 2 SD below the control mean. Vitamin A correlated significantly with RBP $(r=0.62 \quad \mathrm{P}<0.01)$. There was no correlation between vitamin $\mathrm{A}$ and the severity of steatorrhoea $(r=0 \cdot 18 \mathrm{P}>0 \cdot 1)$. The clinical state of the patients, as assessed by the Shwachman score, showed a relationship to plasma vitamin A and RBP. In those with a Shwachman score $<75$, serum vitamin A levels (mean 1.19 $\pm 0 \cdot 161 \mathrm{SE} \mu \mathrm{mol} / \mathrm{l}$ ) were significantly lower $(t=4.08 \mathrm{P}<0.01)$ than in those with a score above 75 (mean $2 \cdot 13 \pm 0 \cdot 101 \mathrm{SE}$ $\mu \mathrm{mol} / \mathrm{l})$. The RBP level was also significantly lower $(t=2.97 \mathrm{P}<0.01$ ) in the $<75$ group (mean $26.0 \pm 2.91 \mathrm{SE} \mu \mathrm{g} / \mathrm{ml})$ compared with the $>75$ group (mean $36 \cdot 0 \pm 1 \cdot 801 \mathrm{SE} \mu \mathrm{g} / \mathrm{ml}$ ).

Vitamin E. Serum vitamin E concentration in the patients (mean 7.7 $\pm 0.811 \mathrm{SE} \mu \mathrm{mol} / \mathrm{l}$ ) was significantly lower $(t=8.6 \mathrm{P}<0.01)$ than in the control group (mean $17.6 \pm 0.871 \mathrm{SE} \mu \mathrm{mol} / \mathrm{l}$ ) (Fig. 4). Twenty-eight $(93 \%$ of the 30 patients had values more than 2 SD below the control mean; 8 $(27 \%)$ had values lower than $5 \mu \mathrm{mol} / \mathrm{l}$, and $21(70 \%)$ had values lower than $10 \mu \mathrm{mol} / \mathrm{l}$. Concentrations of low density lipoproteins ( $\beta$-lipoproteins), which in 
most conditions are the major carrier proteins for vitamin $\mathrm{E}$ in serum, were significantly lower $(t=3.9$ $\mathbf{P}<0.01$ ) in patients (mean $358 \pm 11.81 \mathrm{SE}$ $\mathrm{mg} / 100 \mathrm{ml}$ ) than in controls (mean $440 \pm 21 \cdot 31 \mathrm{SE}$ $\mathrm{mg} / 100 \mathrm{ml}$ ). Surprisingly, there was no significant correlation between serum vitamin $\mathrm{E}$ and $\beta$-lipoprotein $(r=0 \cdot 16)$. Serum vitamin $E$ correlated significantly with faecal fat $(\mathrm{r}=0.55 \mathrm{P}<0.01)$. The clinical grading showed no significant correlation with serum vitamin $\mathrm{E}$, the mean value in the $<75$ group $(8.02 \mu \mathrm{mol} / \mathrm{l})$ being similar to that in the $>75$ group $(6 \cdot 88 \mu \mathrm{mol} / \mathrm{l})$.

Vitamin D. 25-OH-cholecalciferol was measured in 25 patients, 20 of whom were receiving 400 IU vitamin D supplements a day. Twenty-two of the 25 samples were collected between the months of October and April. Four patients had values lower than $10 \mathrm{ng} / \mathrm{ml}, 2$ of whom were not receiving vitamin D supplements. Eight further patients had 25-OH-cholecalciferol levels between 10 and 15 $\mathrm{ng} / \mathrm{ml}$. These values may be considered at the lower end of the normal range; $; 33$ of these 8 were not receiving vitamin $D$ supplements. Thus all 5 patients not receiving vitamin $D$ supplements had serum values lower than $15 \mathrm{ng} / \mathrm{ml}$ and in 2 the values were lower than $10 \mathrm{ng} / \mathrm{ml}$. Of the 20 patients receiving vitamin D supplements, 7 (35\%) had values lower than $15 \mathrm{ng} / \mathrm{ml}$ and $2(10 \%)$ had values lower than $10 \mathrm{ng} / \mathrm{ml}$. There was no significant correlation between serum $25-\mathrm{OH}$-cholecalciferol and severity of steatorrhoea $(r=0 \cdot 17 \mathrm{P}<0 \cdot 1)$.

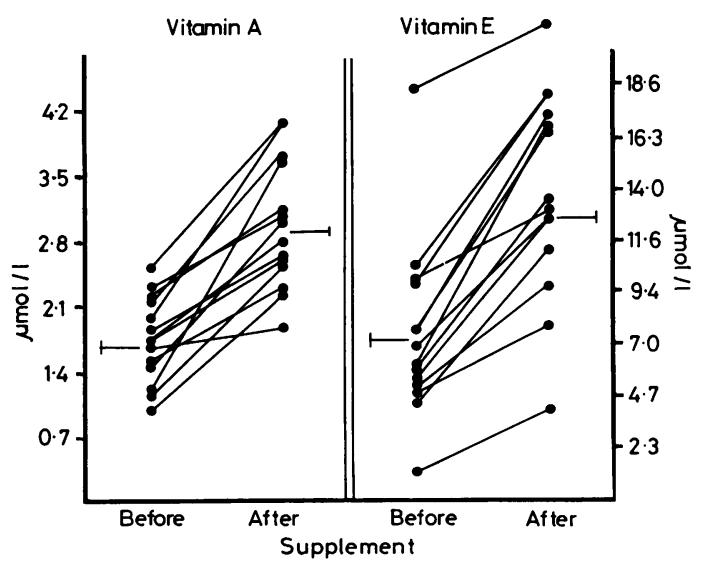

Fig. 5 Response of serum vitamin $A$ and $E$ in 14 patients with cystic fibrosis to short-term (14 days) supplementation with water miscible preparations of vitamin A (4000 IU/day) and vitamin E (50 mg/day). The mean for each group is shown by the horizontal bars and the lines connect the results from individual patients.
Response to supplements. The response of the serum vitamin $A$ and $E$ to oral supplementation for 2 weeks with fairly small doses of water-miscible preparations is shown in Fig. 5. The level of both vitamins rose in all 14 patients. The mean serum vitamin $A$ increased from 1.68 to $3.09 \mu \mathrm{mol} / \mathrm{l}$, while the mean serum vitamin $E$ level increased from $7 \cdot 33$ to $13.0 \mu \mathrm{mol} / \mathrm{l}$, both increases being highly significant $(P<0.01)$. The increase in vitamin $\mathbf{A}$ in individual patients was not related either to the severity of steatorrhoea or to the initial level of RBP. The increase in serum vitamin $E$ was not related to the severity of steatorrhoea or to the level of $\beta$-lipoprotein.

\section{Discussion}

Patients with cystic fibrosis are routinely given water-soluble and fat-soluble vitamin supplements. Administration of the fat-soluble vitamins is readily rationalised by the fact that such patients often have severe fat malabsorption ${ }^{5}$ and consequently fat soluble-vitamin malabsorption. ${ }^{1}$ Dietary intake in children with cystic fibrosis is often well maintained owing to an increased appetite ${ }^{34}$ and absorption of water-soluble vitamins would be expected to be normal so that severe deficiency of water-soluble vitamins seems unlikely.

The roles of vitamin $\mathbf{C}$ and the $\mathbf{B}$ vitamins in human nutrition are complex, and they play many essential roles in maintaining intermediary metabolism ${ }^{35}$ and the immunological defences may depend on adequate nutrition. ${ }^{15}$ The importance of marginal or subclinical water-soluble vitamin deficiency is not understood. Among the many roles ascribed to vitamin $\mathrm{C}$ is its capacity to promote the immune response $^{36}$ and possibly aid in the prevention of infection. ${ }^{37}$ The presence of low or marginally low leucocyte vitamin $\mathrm{C}$ levels in the patients reported here, despite oral supplementation, suggest depleted or inadequate tissue stores. ${ }^{38}$ It has also been stated that patients receiving long-term broad spectrum antibiotics should receive additional vitamins. $^{16}$

To our knowledge there is little, if any, information to suggest that deficiency of water-soluble vitamins occurs in cystic fibrosis, and we do not know of any previous studies on blood levels of vitamin B1, B2, B6, or vitamin C in cystic fibrosis. Reviews of the subject have without exception stated the need for multivitamin supplementation at twice the recommended intake. ${ }^{13173439}$ Chase et al. ${ }^{12}$ have stressed the continuing lack of information on the water-soluble vitamin needs of patients with cystic fibrosis. Based on blood analysis, the patients with cystic fibrosis in the present study showed little, if any, evidence of water-soluble vitamin deficiency and 
this applied equally to those not receiving vitamin supplements.

Severe fat malabsorption is present in a high proportion of patients with cystic fibrosis, ${ }^{56} 40$ and this was confirmed in the present study. Fat malabsorption is widely accepted as the cause of the fat soluble vitamin deficiency, ${ }^{1} 90$ but the relationship has not always been close.

Vitamin $\mathbf{A}$ in serum is present as the free alcohol retinol, almost entirely attached to a specific transport protein, the $\mathrm{RBP},{ }^{\mathbf{4 1} \mathbf{4 2}}$ which is synthesised in the liver. ${ }^{43}$ It has previously been shown that levels of RBP in serum are often low in cystic fibrosis and that a good correlation exists between serum vitamin $\mathrm{A}$ and RBP levels ${ }^{19}$ which may help to explain low serum vitamin A levels. In the present study, although most patients had daily supplements of 4000 IU of vitamin A, a high proportion had low serum levels and there was a good correlation between vitamin A and RBP levels in serum. It is not possible however, to decide the relative contribution of low levels of RBP and inadequate absorption. Adding a small vitamin A supplement as a watermiscible formulation resulted in a prompt and significant increase in serum levels in all patients tested, suggesting perhaps that absorption of the vitamin may have been limiting. Further studies will be required to determine the minimum daily water-miscible vitamin A supplement required to maintain normal serum levels. Because of the dangers of vitamin A toxicity, even at fairly low daily intakes, ${ }^{41} \mathbf{4 4}$ it will be important to determine this minimal daily requirement of water-miscible preparations.

Serum vitamin E levels were low in most of our patients in agreement with previous studies, ${ }^{40} 4546$ and this was correlated with the severity of fat malabsorption. Fat malabsorption is probably the major cause of the vitamin $E$ deficiency although the level of $\beta$ lipoproteins, the major transport protein for vitamin $\mathrm{E},{ }^{47}$ was sometimes low. The clinical significance of vitamin $E$ in human nutrition is debatable, although in the USA it is considered an essential nutrient. ${ }^{48}$ Several reports in cystic fibrosis suggest that supplements should be administered to achieve normal serum levels. ${ }^{40}{ }^{48}$ There is little doubt that water-miscible preparations are more efficiently absorbed than fat-soluble preparations. ${ }^{46}$ Vitamin $\mathrm{E}$ is an antioxidant and may also protect against oxidative destruction of vitamin $A$ and other compounds within the gastrointestinal tract. ${ }^{49} 50$

Severe deficiencies of vitamin D and vitamin $\mathrm{K}$ are rare in cystic fibrosis although rickets ${ }^{8}$ and lifethreatening bleeding ${ }^{9} 51$ have been described. Assay of serum vitamin $\mathrm{K}$ to assess subclinical deficiency is not available, but by competitive protein binding assay of the hydroxylated metabolites of vitamin $\mathrm{D}$, it is now possible to assess the frequency of subclinical vitamin D deficiency. Reports of serum 25-OH-cholecalciferol levels in cystic fibrosis are somewhat conflicting. Thus Hubbard et al..$^{52}$ reported that levels were generally normal during the summer/autumn season in the USA in patients receiving $800 \mathrm{IU}$ orally a day. In contrast, Hahn et $a .^{53}$ also in the USA, found that values for 25-OH-cholecalciferol during March and April were only $60 \%$ of control values despite oral supplements, and $30 \%$ had unequivocally low levels. In the absence of faecal fat measurements in either of these studies, the possible contribution of steatorrhoea cannot be assessed.

The results of the present study by comparison with the values in normal English schoolchildren reported by Poskitt et al. ${ }^{33}$ tend to support those of Hahn et al. ${ }^{53}$ There is, therefore, some indication from the present study that subclinical deficiency of vitamin D may exist in cystic fibrosis even though routine oral supplementation was being given.

This work was supported by a grant from the West Riding Medical Research Trust.

\section{References}

1 Kopel F B. Gastrointestinal manifestations of cystic fibrosis. Gastroenterology 1972; 62: 483-91.

2 Warwick W J, Pogue R E. The prognosis for children with cystic fibrosis based on reasoned approaches to therapy: past, present, and future. J Asthma Res 1968; 5: 277-84.

3 Shwachman H, Redmond A, Khaw K-T. Studies in cystic fibrosis. Report of 130 patients diagnosed under three months of age over a 20-year period. Pediatrics 1970; 46: 335-43.

4 Orenstein D M, Boat T F, Stern R C, et al. The effect of early diagnosis and treatment in cystic fibrosis. Am J Dis Child 1977; 131: 973-5.

5 Goodchild M C, Sagaró E, Brown G A, Cruchley P M, Jukes H R, Anderson C M. Comparative trial of Pancrex $\mathrm{V}$ forte and Nutrizym in treatment of malabsorption in cystic fibrosis. Br Med J 1974; iii: 712-4.

6 Lapey A, Kattwinkel J, Di Sant'Agnese P A, Laster L. Steatorrhea and azotorrhea and their relation to growth and nutrition in adolescents and young adults with cystic fibrosis. J Pediatr 1974; 84: 328-34.

7 Thompson G R. Absorption of fat soluble vitamins and sterols. In: Dawson A M, ed. Intestinal absorption and its derangements. Royal College of Pathologists Symposium No 5. London: British Medical Association, 1971: 85-9.

8 Scott J, Elias E, Moult P J A, Barnes S, Wills M R. Rickets in adult cystic fibrosis with myopathy, pancreatic insufficiency, and proximal renal tubular dysfunction. Am J Med 1977; 63: 488-92.

9 Torstenson O L, Humphrey G B, Edson J R, Warwick W J. Cystic fibrosis presenting with severe hemorrhage due to vitamin $\mathrm{K}$ malabsorption: a report of three cases. Pediatrics 1970; 45: 857-61.

10 Johansen P G, Anderson C M, Hadorn B. Cystic fibrosis of the pancreas. A generalised disturbance of water and electrolyte movement in exocrine tissue. Lancet 1968; i: 455-60. 
11 Anderson C M. Cystic fibrosis of the pancreas. In: Bouchier I A D, ed. Recent advances in gastroenterology. Vol. 3. Edinburgh: Churchill Livingstone, 1976: 297-333.

12 Chase $\mathbf{H}$ P, Long M A, Lavin M H. Cystic fibrosis and malnutrition.J Pediatr 1979; 95: 337-47.

13 McCombs M L. Research in cystic fibrosis: a review. Tex Rep Biol Med 1973; 31 : 615-29.

14 Mitchell-Heggs P, Mearns M, Batten J C. Cystic fibrosis in adolescents and adults. $Q J$ Med 1976; 45: 479-504.

15 Wood R E. Cystic fibrosis: diagnosis, treatment, and prognosis. South Med J 1979; 72: 189-202.

16 Shwachman H, Khaw K-T. Cystic fibrosis. In: Shirkey H C, ed. Pediatric therapy. St Louis: Mosby, 1968 ; 576-96.

17 Mearns M. Cystic fibrosis. Br J Hosp Med 1974; 12: 497-506.

18 Andersen D H. Cystic fibrosis of the pancreas, vitamin A deficiency, and bronchiectasis. J Pediatr 1939; 15: 763-71.

19 Smith F R, Underwood B A, Denning C R, Varma A, Goodman D S. Depressed plasma retinol-binding protein levels in cystic fibrosis. J Lab Clin Med 1972; 80: 423-33.

20 Shwachman H, Kulczycki L L. Long-term study of one hundred and five patients with cystic fibrosis. Am J Dis Child 1958; 96: 6-15.

21 Doershuk C F, Matthews L W, Tucker A S, et al. A 5 -year clinical evaluation of a therapeutic program for patients with cystic fibrosis. J Pediatr 1964 ; 65: 677-93.

22 Denson K W, Bowers E F. The determination of ascorbic acid in white blood cells. A comparison of WBC ascorbic acid and phenolic acid excretion in elderly patients. Clin Sci 1961 ; 21 : 157-62.

23 Schouten H, Statius van Eps L W, Boudier A M S. Transketolase in blood. Clin Chim Acta 1964; 10: 474-6.

24 Nichoalds G E. Assessment of status of riboflavin nutriture by assay of erythrocyte glutathione reductase activity. Clin Chem 1974; 20: 624-8.

25 Stanoluvic M, Miletic D, Stock A. Die Diagnostik des Vitamin B6-Mangels auf Grund der Bestimmung von erythrocytärer L-Aspartat: 2-Oxoglutarat Aminotranspherase: (Glutamat-oxalacetate-Transaminase) und ihr Stimulation in vitro mit Pyridoxal-5'-Phospat. Clin Chim Acta 1968; 17: 353-62.

26 Hansen L J, Warwick W J. A fluorometric micromethod for serum vitamin A. Am J Clin Pathol 1968; 50: 525-9.

27 Varley H. Practical clinical biochemistry. London: Heinemann, 1969: 608.

28 Skinner R K, Wills M R. Serum 25-hydroxyvitamin D assay. Evaluation of chromatographic and non-chromatographic procedures. Clin Chim Acta 1977; 80: 543-54.

29 Fabianek J, DeFilippi J, Rickards T, Herp A. Micromethod for tocopherol determination in blood serum. Clin Chem 1968; 14: 456-62.

30 Hyden S. The recovery of polyethylene glycol after passage through the digestive tract. Kungliga LantbrukShogskolans Annaler 1956; 22: 411-22.

31 Walker B E, Kelleher J, Davies T, Losowsky M S. Chemical faecal fat using single stools. Scand J Gastroenterol 1971; 6: 277-80.

32 van de Kamer J H, Huinink H ten Bokkel, Weyers H A. Rapid method for the determination of fat in feces. J Biol Chem 1949; 177 : 347-55.

33 Poskitt E M E, Cole T J, Lawson D E M. Diet, sunlight, and 25-hydroxy vitamin $D$ in healthy children and adults. Br Med J 1979; i: 221-3.

34 Shwachman H. Gastrointestinal manifestations of cystic fibrosis. Pediatr Clin North Am 1975; 22: 787-805.

35 Moran J R, Greene H L. The B vitamins and vitamin C in human nutrition. Am J Dis Child 1979; 133: 192-9; 308-14.
36 Thomas W R, Holt P G. Vitamin C and immunity: an assessment of the evidence. Clin Exp Immunol 1978; 32: 370-9.

37 Hume R, Weyers E. Changes in leucocyte ascorbic acid during the common cold. Scott Med J 1973; 18: 3-7.

38 Schorah C J. Inappropriate vitamin C reserves: their frequency and significance in an urban population. In: Taylor $\mathrm{T} \mathrm{G}$, ed. The importance of vitamins to human health. Lancaster: MTP Press, 1979: 61-72.

39 Di Sant' Agnese P A, Talamo R C. Pathogenesis and physiopathology of cystic fibrosis of the pancreas (muscoviscidosis). $N$ Engl J Med 1967; 277: 1287-95; $1344-52 ; 1399-408$.

40 Farrell P M, Bieri J G, Fratantoni J F, Wood R E, Di Sant'Agnese P A. The occurrence and effects of human vitamin $\mathrm{E}$ deficiency. A study in patients with cystic fibrosis. J Clin Invest 1977; 60: 233-41.

41 Smith F R, Goodman D S. Vitamin A transport in human vitamin A toxicity. $N$ Engl J Med 1976; 294: 805-8.

42 Kanai M, Raz A, Goodman D S. Retinol binding protein: the transport protein for vitamin $A$ in human plasma. J Clin Invest 1968; 47: 2025-44.

43 Peterson P A, Rask L, Ostberg L, Andersson L, Kamwendo F, Pertoft $H$. Studies on the transport and cellular distribution of vitamin $\mathbf{A}$ in normal and vitamin A-deficient rats with special reference to the vitamin A-binding plasma protein. J Biol Chem 1973;248: 4009-22.

44 Anonymous. Hypervitaminosis A. Ann Intern Med 1974; 80: $105-6$.

45 Levin S, Gordon M H, Nitowsky H M, Goldman C, Di Sant'Agnese P A, Gordon H H. Studies of tocopherol deficiency in infants and children. VI. Evaluation of muscle strength and effect of tocopherol administration in children with cystic fibrosis. Pediatrics 1961 ; 27 : 578-88.

16 Harries J T, Muller D P R. Absorption of different doses of fat soluble and water miscible preparations of vitamin E in children with cystic fibrosis. Arch Dis Child 1971; 46: $341-4$.

47 Davies T, Kelleher J, Losowsky M S. Interrelation of serum lipoprotein and tocopherol levels. Clin Chim Acta 1969; 24: 431-6.

48 National Research Council Food and Nutrition Board. Recommended dietary allowance, eighth revised edition. Washington DC: National Academy of Sciences, 1974: 56-61.

49 Bauernfeind J C, Newmark H, Brin M. Vitamins A and E nutrition via intramuscular or oral route. Am J Clin Nutr 1974; 27 : 234-53.

50 Green J, Bunyan J. Vitamin E and the biological antioxidant theory. Nutrition Abstracts and Reviews 1969; 39: $321-45$.

51 Walters T R, Koch H F. Hemorrhagic diathesis and cystic fibrosis in infancy. Am $J$ Dis Child 1972;124: 641-2.

52 Hubbard V S, Farrell P M, Di Sant'Agnese P A. 25hydroxycholecalciferol levels in patients with cystic fibrosis. J Pediatr 1979; 94: 84-6.

53 Hahn T J, Squires A E, Halstead L R, Strominger D B. Reduced serum 25-hydroxyvitamin $D$ concentration and disordered mineral metabolism in patients with cystic fibrosis. J Pediatr 1979; 94: 38-42.

Correspondence to Dr Jerry Kelleher, Department of Medicine, St James's Hospital, Beckett Street, Leeds LS9 7TF.

Received 1 July 1980 